\title{
Increased Expression of the bcl6 and CD10 Proteins Is Associated with Increased Apoptosis and Proliferation in Diffuse Large B-Cell Lymphomas
}

\author{
M. Bai, M.D., Ph.D. , N. J. Agnantis, M.D., Ph.D., A. Skyrlas, B.Sc., E. Tsanou, M.D., \\ S. Kamina, M.D., Ph.D., V. Galani, B.Sc., Ph.D., P. Kanavaros, M.D., Ph.D. \\ Departments of Pathology (MB, NJA, AS, ET, SK) and Anatomy-Histology-Embryology (VG, PK), Medical \\ Faculty, University of Ioannina, Ioannina, Greece
}

There is increasing evidence that bcl6 and CD10 expression may be related to apoptosis and cell cycle progression. Therefore, 79 cases of de novo diffuse large B-cell lymphomas were studied for the expression of bcl6 and CD10 proteins in relation to 1) the apoptotic index; 2) the proliferationassociated proteins Ki67, cyclin A, and cyclin B1; and 3) the expression of the bcl2, p53, Rb, p16, and p27 proteins. Expression of bcl6, CD10, and bcl2 proteins was found in 54/79 (68\%), 28/79 (35\%), and $47 / 74(63 \%)$ cases, respectively. The bcl6/CD10 patterns were as follows: bcl6+/CD10 + $(26$ cases, $32 \%)$, bcl6+/CD10- (28 cases, 33\%), bcl6-/CD10- (23 cases, $31 \%$ ), and bcl6-/CD10+ ( 2 cases, $4 \%$ ). Significant positive correlations were found between bcl6/Ki67 $(r=.328, P=.003)$, bcl6/cyclin A $(r=$ $.265, P=.018)$, bcl6/apoptotic index $(r=.327, P=$ .010), CD10/Ki67 ( $r=.296, P=.008)$, and CD10/ apoptotic index $(r=.397, P=.001)$. In addition, high expression of bcl6 showed significant correlation with negative (null/low) bcl2 expression $\left(\chi^{2}\right.$ test, $P=.002)$. The above findings indicate that increased expression of the bcl6 and CD10 proteins is associated with increased apoptosis and proliferation in diffuse large B-cell lymphomas. The association between increased bcl6 expression and enhanced apoptosis might be due, at least in part, to the null/low bcl2 expression because previous in vitro data showed that bcl6 overexpression induces apoptosis accompanied by bcl2 and bcl-xl downregulation. Moreover, significant correlation was found between increased apoptotic index and the

Copyright () 2003 by The United States and Canadian Academy of Pathology, Inc.

VOL. 16, NO. 5, P. 471, 2003 Printed in the U.S.A

Date of acceptance: February 20, 2003.

Supported in part by Grant ELE II/2000 from the Research Commission of the University of Ioannina.

Address reprint requests to: Maria Bai, M.D., Ph.D., Department of Pathology, Medical School, University of Ioannina, 45110, Ioannina, Greece; fax: 06510-97895; e-mail: mbai@cc.uoi.gr.

DOI: 10.1097/01.MP.0000067684.78221.6E
bcl6+/CD10+ pattern ( $t$ test: $P=.014$, MannWhitney test: $P=.046)$. This finding and the positive correlation of the apoptotic index with bcl6 and CD10 expression may be related to previous results showing that the expression of these proteins has favorable effects on the clinical outcome of diffuse large B-cell lymphomas.

KEY WORDS: Apoptosis, Bcl6, CD10, Diffuse large B-cell lymphomas, Proliferation.

Mod Pathol 2003;16(5):471-480

Normal tissue homeostasis is maintained by the regulation of cell proliferation and death. This regulation may be achieved, in part, by coupling the process of cell cycle progression and apoptosis by using and controlling a shared set of factors including, among others, the oncosuppressor genes $p 53$ and $R b$, the dominant oncogene $c$-Myc and various cyclin-dependent kinase inhibitors (CDKIs) $(1,2)$. There is now a body of evidence to suggest that the impairment of various regulators of the cell cycle progression and apoptosis plays a crucial role in oncogenesis (1-3).

Diffuse large B-cell lymphomas represent the most common type of non-Hodgkin's lymphomas in Western countries and are characterized by heterogeneous clinical, immunophenotypic, and genetic features (4-10). Given their biological heterogeneity, alterations of several cell cycle and apoptosis regulators have been identified in diffuse large B-cell lymphomas by using immunohistochemical and molecular biology techniques (5-10).

Recently, the global gene expression profile of diffuse large B-cell lymphomas has been analyzed by means of cDNA microarrays $(8,9)$. Alizedeh et al. (8) have identified two molecularly distinct groups of diffuse large B-cell lymphomas, the germinal center B-like diffuse large B-cell lymphomas and the activated B-like diffuse large B-cell lymphomas. This was confirmed by Rosenwald et al. (9) who, in 
addition to the germinal center B-like diffuse large B-cell lymphomas and the activated B-like diffuse large B-cell lymphomas, have also described the type 3 diffuse large B-cell lymphomas. The germinal center B-like diffuse large B-cell lymphomas were characterized by the expression of genes of the normal germinal center B-cells, the activated B-like diffuse large B-cell lymphomas were characterized by the expression of genes that are normally induced during in vitro activation of peripheral blood B-cells and the Type 3 diffuse large B-cell lymphomas did not express either set of genes at a high level $(8,9)$. The gene expression signature of the germinal center B-like diffuse large B-cell lymphomas included several known germinal center differentiation markers (e.g., bcl6, CD10, CD38) and a host of new genes (e.g., $B C L-7 A, L M O 2 ; 8)$. The gene expression signature of the activated B-like diffuse large B-cell lymphomas included a gene that is translocated in lymphoid malignancies, IRF4 (MUM1/LSIRF), and two noteworthy genes whose products inhibit apoptosis, FLIP and bcl2 (8). Moreover, these molecularly distinct types of diffuse large B-cell lymphomas were also found to be distinct with respect to prognosis. The patients with germinal center B-like diffuse large B-cell lymphomas had more favorable clinical outcome than those with activated B-like diffuse large B-cell lymphomas $(8,9)$.

Bcl6 protein is a POZ/zinc finger sequencespecific transcriptional repressor that was found to be required for germinal center formation, antibodyaffinity maturation, and T-helper-2-mediated responses (11-13). Bcl6 inhibits lymphocyte activation by inhibiting the expression of CD69 and CD44 and inhibits differentiation of germinal center $\mathrm{B}$ cells toward plasma cells by inhibiting the expression of Blimp-1 gene, which is important for plasmacytic differentiation (13). Chromosomal translocations involving the 5 ' noncoding domain of the bcl6 gene at band 3q27 are observed in about $40 \%$ of diffuse large B-cell lymphomas and $10-15 \%$ of follicular B-cell lymphomas, juxtaposing the gene to promoters from a variety of partner chromosomes (most commonly in immunoglobulin heavy chain loci; 13, 14-20). Mutations within the 5' noncoding domain of the bcl6 gene occur frequently in germinal center and post- germinal center lymphomas, including diffuse large B-cell lymphomas, follicular B-cell lymphomas and Burkitt lymphomas $(13,20-23)$. Expression of the bcl6 protein occurs almost always in follicular B-cell lymphomas and frequently in diffuse large B-cell lymphomas and Burkitt lymphomas, but it appears that bcl6 protein expression is not associated with alterations of the bcl6 gene (20, 24-32).

CD10 protein is a cell surface metalloproteinase that reduces cellular response to peptide hormones
$(28,33)$. Identified substrates are largely neural or humoral oligopeptide agonists and the enzyme functions to terminate signaling by degrading the ligand (33). Among hematopoietic cells, CD10 is expressed by immature B and T cells, by the germinal center B cells, by granulocytes, and by cells of a number of lymphoid malignancies $(4,5,10,33)$. Regarding B-cell non-Hodgkin's lymphomas, CD10 protein is expressed in almost all Burkitt lymphomas, in most follicular B-cell lymphomas, and in a proportion of diffuse large B-cell lymphomas, whereas marginal zone/mucosa associated lymphoid tissue (MALT) lymphomas and mantle cell lymphomas are CD10 negative (10, 24, 27-35).

There is increasing evidence that bcl6 and CD10 expression may be related to apoptosis and cell cycle progression. Indeed, data from in vitro studies indicate that the role of bcl6 as promotor or inhibitor of apoptosis or proliferation may depend on the cellular context and the experimental approach (36-46). In addition, in vitro studies and studies of normal lymphoid tissue and lymphoid malignancies showed that the expression of CD10 protein is associated with apoptosis and proliferation $(4,5,10$, 47-51). However, to the best of our knowledge, there is no detailed histological information about the relation of bcl6 and CD10 expression status with apoptosis and proliferation in diffuse large B-cell lymphomas. Therefore, we have investigated the immunohistochemical expression of the bcl6 and CD10 proteins and the bcl6/CD10 expression patterns in relation to (1) the apoptotic index, (2) the proliferation profile (expression of Ki67, cyclin A, and cyclin B1 proteins), and (3) the expression of major regulators of the cell cycle and/or the apoptosis such as bcl2, p53, Rb, p16, and p27 proteins in 79 cases of de novo diffuse large B-cell lymphomas.

\section{MATERIALS AND METHODS}

\section{Materials}

Seventy-nine cases of de novo diffuse large B-cell lymphomas (37 nodal and 42 extranodal) classified according to the Revised European-American classification of lymphoid neoplasms (REAL classification) (4) were selected from the files of the Department of Pathology of the University of Ioannina on the basis that complete clinicopathological parameters were available.

\section{Immunohistochemistry}

Immunostainings were performed on formalinfixed, paraffin-embedded tissue sections by the labeled streptavidin avidin biotin method using monoclonal antibodies directed against bcl6 (dilu- 
tion 1:10, clone PG-B6p, Dako SA, Glostrup, Denmark), CD10 (dilution 1:10, clone 56C6, Novocastra, Newcastle upon Tyne, UK), and bcl2 proteins (dilution 1:10, clone 124, Dako SA, Glostrup, Denmark). Pretreatment of the sections with the buffer Dako-code S3308 in microwave oven twice for 5 minutes each was performed for the bcl6 immunostaining. Pretreatment of the sections with $10 \mathrm{~mm}$ sodium citrate buffer (ph 6.0) in a microwave oven was performed for the CD10 and bcl2 immunostaining as we described elsewhere (52). The monoclonal antibodies directed against Ki67, cyclin A, cyclin B1, p53, Rb1, p16, and p27 proteins, the corresponding positive controls, and the evaluation approach for the expression status of these proteins were reported in detail elsewhere (53). Briefly, positive expression of p53 was considered when the expression of this protein in large neoplastic cells was higher than the maximum value of the expression in lymphoid cells in the reactive lymphoid tissues. Positive expression of p27 was considered when the expression of this protein in large neoplastic cells was higher than the maximum value of the expression in large lymphoid cells in the reactive lymphoid tissues. Rb- or p16-negative expression (partial or total) was considered when the large neoplastic cells were negative and interspersed nuclei of reactive cells (small lymphocytes, endothelial cells) were positive. For the counting of immunopositive bcl6, CD10, and bcl 2 cells a continuous score system was adopted by using the $40 \times$ objective lens and counting at least five fields selected on the basis that they contained immunopositive cells. The number of immunopositive cells was divided by the total number of the counted cells, and the expression was defined as the percentage of positive cells in the total number of the counted cells. Three groups of immunoexpression were defined: less than 10\%: null/low, 10-29\%: intermediate, and at least 30\%: high expression. Positive expression of bcl6, CD10 and bcl2 proteins was considered the intermediate/high expression and negative expression was considered the null/low expression. Internal positive control was required and reactive lymph nodes and normal thymuses from our previous studies were also used as positive controls $(53,54)$. Negative controls were included and consisted in the same immunohistochemical method with omission of the primary antibody.

\section{TUNEL Method}

The TdT (terminal deoxynucleotidyl-transferase)mediated in situ labeling technique (TUNEL; Apotag kit, Oncor, Gaithersburg, MD) was carried out as we described in details in a previous study (55). Positive and negative controls were included in every staining. Reactive lymph nodes and thymuses served as positive controls. Negative controls consisted in the same method with omission of the TdT reaction step. The evaluation of the results was performed as we described previously $(54,55)$. Briefly, morphologically intact TUNEL-positive cells and apoptotic cells in hematoxylin-eosin stained slides (defined as cells with condensed, hyperchromatic, ring-like, crescentic, or beaded chromatin and often surrounded by a clear halo) were considered as positive and are referred to as apoptotic cells. Areas of obvious necrosis were excluded from counting. The number of apoptotic cells was recorded by using the $40 \times$ objective lens and by counting the apoptotic cells in at least 10 randomly selected fields, corresponding to a total of 2000 to 3000 cells. The apoptotic index was determined as the number of apoptotic cells expressed as a percentage of the total number of counted cells.

\section{Statistical Analysis}

The $t$ test and Mann-Whitney test (for comparison of two groups of cases on one variable), $\chi^{2}$ test (for comparison of categorical data), and Spearman's correlation test (for assessment of correlation between two continuous variables) were used. The values of the Spearman's correlation coefficients are presented as $r$ values. The results were considered as statistically significant when $P<.05$. The program SPSS for Windows Release 10 was used for statistical analysis.

\section{RESULTS}

Immunohistochemical expression of the bcl6 (Fig. 1), CD10 (Fig. 2), and bcl2 proteins was found in 54/79 (68\%), 28/79 (35\%), and 47/74 (63\%) cases, respectively (Table 1 ). The bcl6/CD10 patterns were as follows: bcl6+/CD10+ (26 cases, $32 \%)$, bcl6+/ CD10 - (28 cases, 33\%), bcl6-/CD10- (23 cases, $31 \%)$ and bcl6-/CD10+ (2 cases, $4 \%$; Table 2$)$. The apoptotic index (54) could be evaluated in 62 cases (range, $0.26-9.7 \%$, mean value $2.79 \% \pm 1.97 \%$; Fig 3). The expression of p27, p53, Rb, p16, Ki67, cyclin A, and cyclin B1 proteins was reported in details previously (53). Briefly, positive expression of p27 and p53 proteins was observed in 22/79 (28\%) and $38 / 79$ (48\%) cases, respectively. Negative expression of $\mathrm{Rb}$ and $\mathrm{p} 16$ proteins was mutually exclusive and was observed in 5/79 (7\%) and 14/79 (18\%) cases, respectively. The expression of cyclin A and cyclin B1 was high (at least $30 \%$ of neoplastic cells positive) in $44 / 79(56 \%)$ and $22 / 79$ (27\%) cases, respectively, and was intermediate/low in the remaining cases.

The immunoexpressions of the bcl6, CD10, Ki67, cyclin A, cyclin B1, bcl2, p53, Rb, p16, and p27 pro- 


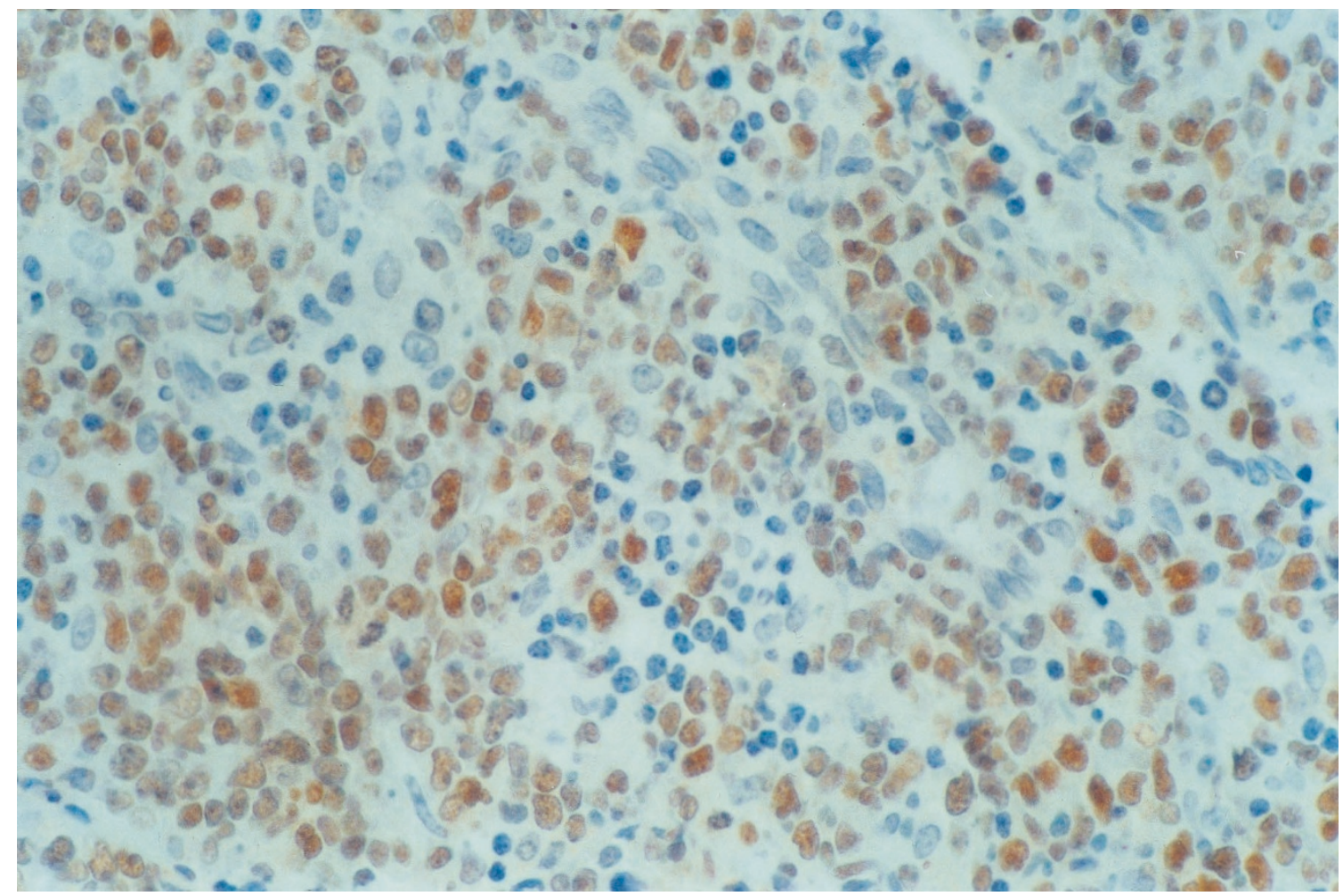

FIGURE 1. High bcl6 immunohistochemical expression in neoplastic cells of diffuse large B-cell lymphomas (magnification $400 \times$ ).

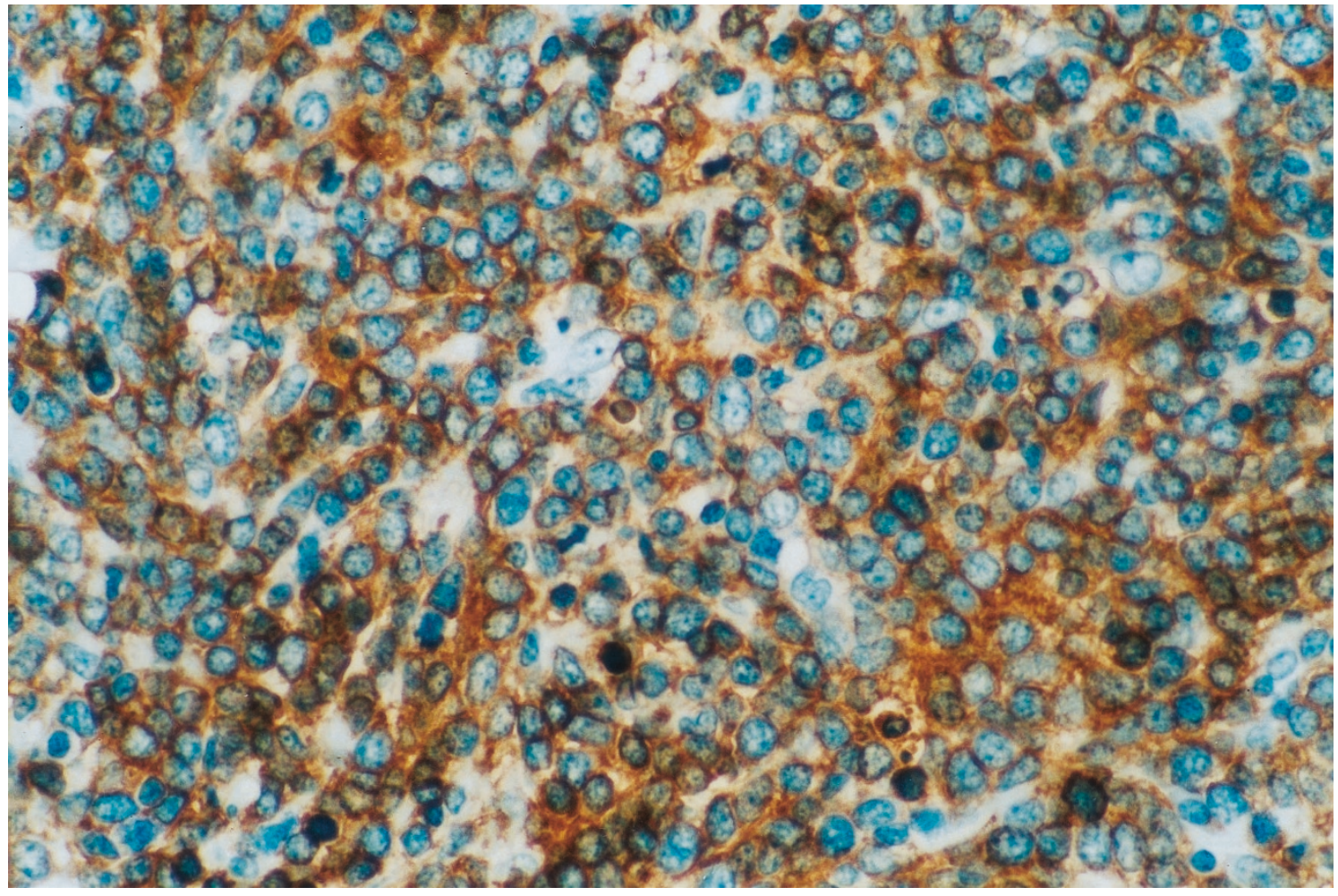

FIGURE 2. High CD10 immunohistochemical expression in neoplastic cells of diffuse large B-cell lymphomas (magnification $400 \times$ ).

teins and the apoptotic index were analyzed as continuous variables and significant positive correlations were found between bcl6/Ki67 $(r=.328, P=.003)$, bcl6/cyclin A $(r=.265, P=.018)$, bcl6/apoptotic index $(r=.327, P=.010)$, CD10/Ki67 $(r=.296, P=$ $.008)$, and CD10/apoptotic index $(r=.397, P=.001)$.

The expression status (positive versus negative cases) of bcl6 and CD10 proteins was analyzed in 
TABLE 1. Expression Status of bcl6, CD10, and bcl2 Proteins

\begin{tabular}{lccc}
\hline \multicolumn{1}{c}{ Expression Status } & Bcl6 & CD10 & Bcl2 \\
\hline High expression & $24(30 \%)$ & $7(9 \%)$ & $43(58 \%)$ \\
Intermediate expression & $30(38 \%)$ & $21(26 \%)$ & $4(5 \%)$ \\
Total positive cases & $54(68 \%)$ & $28(35 \%)$ & $47(63 \%)$ \\
Negative expression & $25(32 \%)$ & $51(65 \%)$ & $27(37 \%)$ \\
Total cases & 79 & 79 & 74 \\
\hline
\end{tabular}

High expression: at least $30 \%$ of neoplastic cells positive. Intermediate expression: $10-29 \%$ of neoplastic cells positive.

Negative expression: less than $10 \%$ of neoplastic cells positive.

TABLE 2. Expression Patterns of bcl6 and CD10 Proteins

\begin{tabular}{cc}
\hline Patterns & Number of Cases \\
\hline bcl6+/CD10+ & $26(32 \%)$ \\
bcl6+/CD10- & $28(33 \%)$ \\
bcl6-/CD10+ & $2(4 \%)$ \\
bcl6-/CD10- & $23(31 \%)$ \\
Total & 79 \\
\hline
\end{tabular}

relation to the expression status (positive versus negative cases) of the bcl2, p27, p53, Rb, and p16 proteins (Tables 3 and 4). Significant correlation was found between high expression of the bcl6 protein and negative expression status of the bcl2 protein (Fisher's $\chi^{2}$ test: $P=.002$; Table 4 ).

Because both bcl6 and CD10 were positively correlated with apoptosis and proliferation, the bcl6+I $\mathrm{CD} 10+$ expression pattern (versus the other bcl6/ CD10 patterns) was analyzed in relation to the values of the apoptotic index (Table 5) and in relation to the expression status of Ki67, cyclin A, cyclin B1, bcl2, p27, p53, Rb, and p16 proteins (Table 6). Significant correlation was found between bcl6+ I CD10+ pattern and increased apoptotic index ( $t$ test: $P=.014$, Mann-Whitney test: $P=.046$; Table 5).

\section{Correlation with Clinicopathological Parameters}

No significant correlation was found between tumor localization (nodal versus extranodal) or tumor stage (I-IV) and expression status of bcl6, CD10 or bcl6/CD10 patterns.

\section{DISCUSSION}

The main finding of the present study was that increased expression of the bcl6 and CD10 proteins is associated with increased apoptosis and proliferation in diffuse large B-cell lymphomas. With respect to bcl6, the data in the literature indicate that its role as promotor or inhibitor of apoptosis may depend on the cellular context and the experimental approach $(37,41-46)$. Some studies reported that bcl6 may protect cells from apoptosis (41, 43, 45). Kumagai et al. (41) used a differentiationinducible mouse myogenic cell line and found that adenovirus-mediated overexpression of bcl6 en- hanced the viability of the differentiating myocytes preventing apoptosis. Kojima et al. (43) used bcl6deficient mice, and they showed that bcl6 may play a role as a stabilizer in protecting spermatocytes from apoptosis induced by stressors such as heat shock. Baron et al. (45) used the Epstein-Barr virusnegative Burkitt lymphoma BJAB cell line expressing high levels of bcl6, and they found that the human programmed cell death-2 (PDCD2) gene is a target of bcl6 repression. Moreover, they showed by immunohistochemical studies of human tonsils that the localization of PDCD2 expression is inversely related to that of bcl6 in germinal center and follicular mantle cells. Therefore, they suggested that bcl6 may down-regulate apoptosis by means of its repressive effects on the human programmed cell death-2 (PDCD2) gene. However, some other studies noted that high expression of bcl6 may induce apoptosis (37, 42, 44, 46). Indeed, Zhang et al. (44) found that overexpression of bcl6 induces apoptosis in murine fibroblast NIH3T3 cells and showed that a 17 aminoacid sequence in the middle portion of bcl6 is responsible for inducibility of apoptosis in these cells. Albagli et al. (37) used the human osteosarcoma cell line U2OS stably transfected with bcl6 and found that bcl6 induces dosedependent growth suppression which was correlated with delayed $S$ phase progression and triggering of apoptosis. Yamoshi et al. (42) found that viability of CV1 and HeLa cells infected by a recombinant adenovirus expressing bcl6 was markedly reduced due to apoptosis. Bcl6 overexpression induced apoptosis which was preceded by downregulation of bcl2 and bcl-xl, and it was suggested that bcl6 might regulate the expression of these apoptosis repressors (42). In keeping with the latter study (42), Tang et al. (46) showed that the forkhead transcription factor AFX activates apoptosis by induction of bcl6 which directly binds to and suppresses the promoter of the antiapoptotic gene $b c l$ $x l$. Our data could be relevant to the results of Yamoshi et al. (42) because we found that high expression of bcl6 showed significant correlation with negative (null/low) bcl2 expression status $(P=$ .002). Moreover, Larocca et al. (25) showed that in most cases of primary central nervous system diffuse large B-cell lymphomas with increased bcl6 expression, the bcl 2 protein was undetectable. On the basis of the aforementioned results it could be hypothesized that the association between increased bcl6 expression and increased apoptosis in diffuse large B-cell lymphomas might be due, at least to some extend, to bcl2 downregulation induced by bcl6 overexpression. However, it is also possible that, at least in a portion of diffuse large B-cell lymphomas, bcl6 may exert its proapoptotic function independently of bcl2 downregulation and possibly through bcl-xl downregulation $(42,46)$, be- 


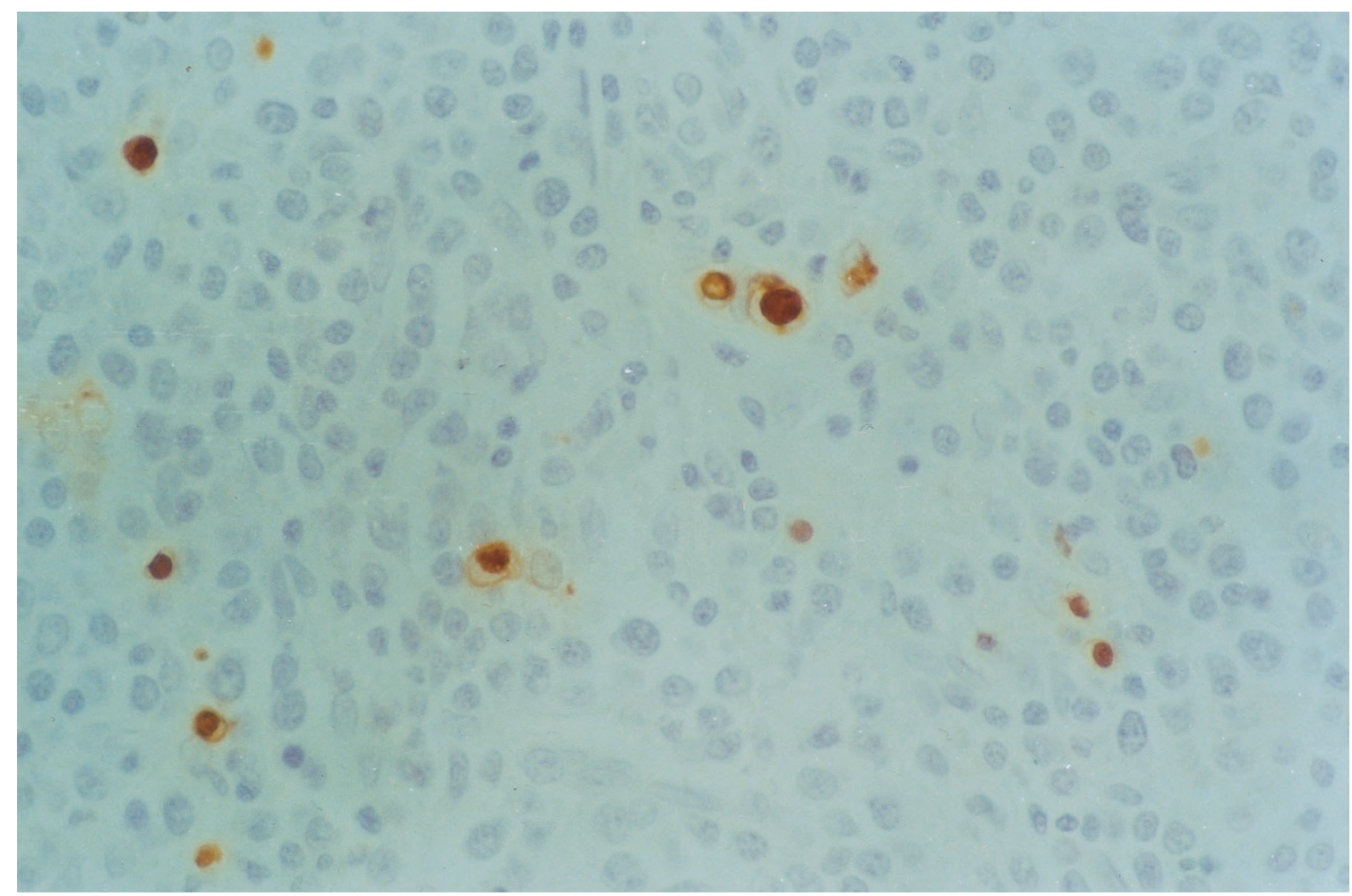

FIGURE 3. Staining of apoptotic cells by the TUNEL method (magnification $400 \times$ ).

TABLE 3. Relation of bcl6 and CD10 with p53, Rb, p16, and p27 Expression Status

\begin{tabular}{lcccc}
\hline & $\begin{array}{c}\text { bcl6+ } \\
(n=54)\end{array}$ & $\begin{array}{c}\text { bcl6- } \\
(n=25)\end{array}$ & $\begin{array}{c}\text { CD10+ } \\
(n=28)\end{array}$ & $\begin{array}{c}\text { CD10- } \\
(n=51)\end{array}$ \\
\hline $\mathrm{p} 53+(\mathrm{n}=38)$ & 25 & 13 & 13 & 25 \\
$\mathrm{p} 53-(\mathrm{n}=41)$ & 29 & 12 & 15 & 26 \\
$\mathrm{Rb}+(\mathrm{n}=74)$ & 51 & 23 & 26 & 48 \\
$\mathrm{Rb}-(\mathrm{n}=5)$ & 3 & 2 & 2 & 3 \\
$\mathrm{p} 16+(\mathrm{n}=65)$ & 46 & 19 & 25 & 40 \\
$\mathrm{p} 16-(\mathrm{n}=14)$ & 8 & 6 & 3 & 11 \\
$\mathrm{p} 27+(\mathrm{n}=22)$ & 15 & 7 & 7 & 15 \\
$\mathrm{p} 27-(\mathrm{n}=57)$ & 39 & 18 & 21 & 36 \\
\hline
\end{tabular}

Chi-Square tests: bcl6 vs p53 ( $P=0.409)$, bcl6 vs Rb ( $P=0.509)$, bcl6 vs p16 ( $P=0.245)$, bcl6 vs. p27 ( $P=0.593), \mathrm{CD} 10$ vs p53 $(P=0.506), \mathrm{CD} 10$ vs $\mathrm{Rb}(P=0.585), \mathrm{CD} 10$ vs p16 ( $P=0.185), \mathrm{CD} 10$ vs $27(P=0.443)$.

TABLE 4. Relation between bcl6 and bcl2 Protein Expression Status

\begin{tabular}{lccc}
\hline \multirow{2}{*}{ bcl6 Expression } & \multicolumn{2}{c}{ Bcl2 Expression } & \multirow{2}{*}{ Total Cases } \\
\cline { 2 - 3 } & High/Intermediate & Negative & \\
\hline High & 9 & 15 & 24 \\
Intermediate/negative & 38 & 12 & 50 \\
Total cases & 47 & 27 & 74 \\
\hline
\end{tabular}

Chi-square test: $P=0.002$.

cause nine cases in our study and four cases in the study Larocca et al. (25) with increased bcl6 expression also expressed bcl 2 protein in a substantial proportion of neoplastic cells (range of bcl2 expression $10-90 \%)$. Clearly, further studies are required to elucidate the relation between bcl6 and apoptosis in diffuse large B-cell lymphomas.

In the present study, bcl6 expression showed significant positive correlation with the proliferationassociated proteins Ki67 and cyclin A. It appears from the literature that there is no simple correlation between bcl6 and proliferation (36-40). Some in vitro studies reported that bcl6 expression was associated with impaired cell cycle progression and decreased proliferation $(37,39)$. Indeed, Albagli et al. (37) showed that bcl6 mediates growth suppression associated with impaired $S$ phase progression in human U2OS osteosarcoma cells. Moreover, Hosokawa et al. (39) established Ba/F3 pro-B cells carrying a human bcl6 transgene and showed that induced bcl6 protein down-regulates the expression of cyclin A2 and inhibits cell proliferation. However, Shaffer et al. (38) showed that bcl6 may promote cell cycle progression and maintain proliferation by repressing the expression of the CDKI p27 and by blocking blimp-1 expression which represses c-myc expression. Moreover, Allman et al. (36) showed that bcl6 protein expression was 34fold higher in the rapidly proliferating germinal center B-cells than in the resting B-cells. Interestingly, a recent study has linked bcl6 expression, senescence response and proliferative capacity of primary human B cells (40). Indeed, Shvarts et al. (40) showed that bcl6 overrides the senescence response downstream of p53 through a process that requires cyclin D1 expression and significantly ex- 


\begin{tabular}{lcc}
\hline \multicolumn{1}{c}{ bcl6/CD10 Patterns } & $n$ & $\begin{array}{c}\text { Apoptotic Index } \\
\text { Mean } \pm \text { SD }\end{array}$ \\
\hline bcl6+/CD10+ & 23 & $\begin{array}{c}\text { Apoptotic Index } \\
\text { Mean Ranks }\end{array}$ \\
bcl6+/CD10-, bcl6-/CD10+ and bcl6-/CD10- & 39 & $3.59 \% \pm 2.52 \%$ \\
Total cases & 62 & $2.32 \% \pm 1.39 \%$ \\
\hline
\end{tabular}

T-test: $P=0.014$, Mann-Whitney test: $P=0.046$.

Mean ranks: the summary of the ranks divided by the number of cases.

TABLE 6. Relation of the bcl6/CD10 Patterns with p53, Rb, p16, p27, bcl2, cyclin A, and cyclin B1 Expression Status

\begin{tabular}{|c|c|c|}
\hline & $\begin{array}{c}\text { bcl6 }+/ \text { CD } 10+\text { Pattern } \\
(n=26)\end{array}$ & $\begin{array}{c}\text { bcl6 }+/ \text { CD10 }-, \text { bcl6 }-/ C D 10+\text { and } \\
\text { bcl6-/CD10 }- \text { Patterns }(n=53)\end{array}$ \\
\hline $\mathrm{p} 53+(n=38)$ & 13 & 25 \\
\hline $\mathrm{p} 53-(n=41)$ & 13 & 28 \\
\hline $\mathrm{Rb}+(n=74)$ & 24 & 50 \\
\hline $\mathrm{Rb}-(n=5)$ & 2 & 3 \\
\hline $\mathrm{p} 16+(n=65)$ & 23 & 42 \\
\hline $\mathrm{p} 16-(n=14)$ & 3 & 11 \\
\hline $\mathrm{p} 27+(n=22)$ & 6 & 16 \\
\hline $\mathrm{p} 27-(n=57)$ & 20 & 37 \\
\hline $\mathrm{bcl} 2+(n=47)$ & 14 & 33 \\
\hline bcl2- $(n=27)$ & 11 & 16 \\
\hline Cyclin A high expression $(n=44)$ & 14 & 30 \\
\hline Cyclin A intermediate/low expression $(n=35)$ & 12 & 23 \\
\hline Cyclin B1 high expression $(n=22)$ & 11 & 11 \\
\hline Cyclin B1 intermediate/low expression $(n=57)$ & 15 & 42 \\
\hline
\end{tabular}

Chi-square tests: bcl6/CD10 patterns vs p53 $(P=0.501)$, vs Rb $(P=0.535)$, vs p16 $(P=0.248), v s . \mathrm{p} 27(P=0.351), v s$ bcl2 $(P=0.240), v s$ cyclin A $(P=$ 0.502), vs cyclin $\mathrm{B} 1(P=0.062)$

tends the replicative lifespan of primary human B cells in culture. They suggested that bcl6 acts as an immortalizing oncogene by rendering cells unresponsive to antiproliferative signals emanating from the p19 (ARF)-p53 pathway during the senescence response. On the basis of the aforementioned results it could be hypothesized that the association between bcl6 and proliferation in diffuse large B-cell lymphomas might be due, at least to some extent, to the possibility that bcl6 confers resistance to antiproliferative signals from the p19 (ARF)-p53 pathway and to down-regulate the expression of the CDKI p27. In this context, the occurrence of aberrations in the p27 expression status and in the p19 (ARF)-p53 and/or Rb-p16-cyclin D growthinhibitory pathways $(1,2)$, which are frequent events in diffuse large B-cell lymphomas (53, 5658), might further enhance the proliferative activity of neoplastic cells. Our recent findings are relevant to this assumption because we have shown that low p27 expression combined with altered $\mathrm{p} 53 / \mathrm{Rb} / \mathrm{p} 16$ expression status is significantly associated with enhanced proliferation in diffuse large B-cell lymphomas (53). In this regard, we asked the question whether bcl6 expression was associated with altered expression of the major cell cycle regulators p27, p53, Rb and p16. However, no significant cor- relations were found, thereby suggesting that further studies are required to elucidate the mechanisms explaining the association between bcl6 and proliferation in diffuse large B-cell lymphomas.

In addition to bcl6, CD10 expression was also positively correlated with the apoptotic index and the proliferation-associated protein Ki67 in the present study. There are several lines of evidence indicating a positive correlation of CD10 expression with proliferation and apoptosis in both normal and malignant B-cells. Indeed, (1) germinal center cells are characterized by high proliferation and have the propensity to undergo apoptosis and upregulate CD10 expression on apoptotic induction, whereas CD10 is absent on other subsets of mature B-cells that are not characterized by high apoptosis $(47,48,51)$, (2) Burkitt's lymphoma cells that are characterized by high proliferation and apoptosis almost constantly express $\operatorname{CD} 10(4,5,10)$, and (3) CD10-positive B-acute lymphoblastic leukemia cells were cycling cells with elevated c-myc and propensity to apoptosis, whereas CD10-negative B-acute lymphoblastic leukemia cells had lower cycling capacities and c-myc levels and were resistant to apoptosis (50). Moreover, human postthymic and thymic T-cells express CD10 when undergoing apoptosis (49). To explain the relations between 
CD10 and apoptosis it was suggested that CD10 might degrade cytokines that reach the cell when apoptosis has already started (49). Because a variety of cytokines may play a protective role in B- and T-cell apoptosis, CD10 expression may potentiate the apoptotic ability of $\mathrm{B}$ and $\mathrm{T}$ cells, by inhibiting the protective signals. As suggested by Cutrona $e t$ al. (49), this could be consistent with the capacity of CD10 to hydrolyze a variety of active peptides, including growth and chemotactic factors. It is possible that CD10 participates in the process of selection in the germinal center and the thymus by increasing the threshold of cytokines required to prevent B and T-cell apoptosis, respectively.

The present findings that bcl6 and CD10 expression is positively correlated with the apoptotic index and that the bcl6+/CD10+ pattern is associated with increased apoptotic index may be related with the results of recent studies reporting that the expression of these proteins has favorable effects on the clinical outcome of diffuse large B-cell lymphomas $(8,9,23,31,34,59)$. Therefore, it could be hypothesized that diffuse large B-cell lymphomas expressing CD10 and bcl6 proteins may be more susceptible to apoptosis and, as a consequence, may be more sensitive to treatment.

In conclusion, the present study shows (1) that increased expression of the bcl6 and CD10 proteins is associated with increased apoptosis and proliferation in diffuse large B-cell lymphomas and (2) that high expression of bcl6 is associated with negative (null/low) bcl2 expression status. The association between increased bcl6 expression and enhanced apoptosis might be due, at least in part, to the null/low bcl2 expression because previous in vitro data showed that bcl6 overexpression induces apoptosis accompanied by bcl2 and bcl-xl downregulation. Moreover, the positive correlation of both bcl6 and CD10 expression with apoptosis and the association of the bcl6+/CD10+ pattern with increased apoptosis may be related to recent results showing that the expression of these proteins has favorable effects on the clinical outcome of diffuse large B-cell lymphomas. Therefore, it could be hypothesized that diffuse large B-cell lymphoma cells expressing CD10 and bcl6 proteins may be more susceptible to apoptosis and, as a consequence, may be more sensitive to treatment.

Acknowledgments:The authors are grateful to Antigoni Christodoulou for her excellent technical assistance.

\section{REFERENCES}

1. Lundberg AS, Weinberg RA. Control of the cell-cycle and apoptosis. Eur J Cancer 1999;35:1886-94.
2. Sherr CJ. The Pezcoller lecture: cancer cell cycles revisited. Cancer Res 2000;60:3689-95.

3. Evan GI, Vousden KH. Proliferation, cell cycle and apoptosis in cancer. Nature 2001;411:342-8.

4. Harris NL, Jaffe ES, Stein H, Bankes PM, Chay JK, Cleary ML, et al. Revised European-American classification of lymphoid neoplasms. A proposal from the International Lymphoma Study Group. Blood 1994;84:1361-92.

5. Gatter KC, Warnke RA. Diffuse large B-cell lymphoma. In: Jaffe ES, Harris NL, Stein H, Vardiman JW, editors. World Health Organization classification of tumours. Pathology and genetics of tumours of the haematopoietic and lymphoid tissues. Lyon, France: International Agency for Research on Cancer (IARC) Press; 2001. p.171-4.

6. Harris NL, Stein H, Coupland SE, Hummel M, Favera RD, Pasqualucci L, et al. New approaches in lymphoma diagnosis. Hematology (Am Soc Hematol Educ Program) 2001;194220:

7. Kuppers R, Klein U, Hansmann ML, Rajewsky K. Cellular origin of human B-cell lymphomas. N Engl J Med 1999;20: $1520-9$.

8. Alizadeh AA, Eisen MB, Davis RE, Ma C, Lossos IS, Rosenwald A, et al. Distinct types of diffuse large B-cell lymphoma identified by gene expression profiling. Nature 2000;403:503-11.

9. Rosenwald A, Wright G, Chan WC, Connors JM, Campo E, Fischer RI, et al. The use of molecular profiling to predict survival after chemotherapy for diffuse large B-cell lymphoma. N Engl J Med 2002;346:1937-47.

10. Pileri SA, Ascani S, Sabatini E, Fraternali-Orcioni G, Poggi S, Piccioli M, et al. The pathologist's view point. Part IIaggressive lymphomas. Haematologica 2000;85:1308-21.

11. Dent AL, Shatter AL, Yu X, Allman D, Staudt LM. Control of inflammation, cytokine expression, and germinal center formation by BCL-6. Science 1997;276:589-92.

12. Ye BH, Cattoretti G, Shen Q, Zhang J, Hawe N, De Waard R, et al. The BCL-6 proto-oncogene controls germinal-centre formation and Th2-type inflammation. Nat Genet 1997;16: 161-70.

13. Dent AL, Vasanwala FH, Toney L. Regulation of gene expression by the proto-oncogene BCL-6. Crit Rev Oncol Hematol 2002;41:1-9.

14. Lococo F, Ye BH, Lista F, Corradini P, Offit K, Knowles DM, et al. Rearrangements of the BCL6 gene in diffuse large cell non-Hodgkin's lymphoma. Blood 1994;83:1757-9.

15. Otsuki T, Yano T, Clark HM, Bastard C, Kerckaert JP, Jaffe ES, et al. Analysis of LAZ3 (BCL6) status in B-cell non-Hodgkin lymphomas: Results of rearrangement and gene expression studies and a mutational analysis of coding region sequences. Blood 1995;85:2877-84.

16. Offit K, Louie DC, Parsa NZ, Roy P, Lo Coco F, Zelenetz A, et al. Bcl6 gene rearrangement and other cytogenetic abnormalities in diffuse large cell lymphoma. Leuk Lymphoma 1995;20:85-9.

17. Ohno H, Fukuhara S. Significance of rearrengement of the bcl6 gene in B-cell lymphoid neoplasms. Leuk Lymphoma 1997;27:53-63.

18. Kramer MH, Hermans J, Wijburg E, Philippo K, Geelen E, van Kricken JH, et al. Clinical relevance of BCL2, BCL6, and MYC rearrangements in diffuse large B-cell lymphoma. Blood 1998;92:3152-62.

19. Kawasaki C, Ohshima K, Suzumiya J. Rearrangements of bcl-1, bcl-2, bcl-6 and c-myc in diffuse large B-cell lymphoma. Leuk Lymphoma 2001;42:1099-1106.

20. Falini B, Mason DY. Proteins encoded by genes involved in chromosomal alterations in lymphoma and leukaemia: clinical value of their detection by immunocytochemistry. Blood 2002;99:409-26. 
21. Capello D, Vitolo U, Pasqualucci L, Quattrone S, Migliaretti G, Fassone L, et al. Distribution and pattern of BCL-6 mutations throughout the spectrum of B-cell neoplasia. Blood 2000;95:651-9.

22. Go JH, Yang WI, Ree HJ. Mutational analysis of the 5'noncoding region of the BCL- 6 gene in primary gastric lymphomas. Mod Pathol 2001;14:410-4.

23. Artiga MJ, Saez AI, Romero C, Sanchez-Beato M, Mateo MS, Navas C, et al. A short mutational hot spot in the first exon of BCL- 6 is associated with increased BCL- 6 expression and with longer overall survival in large B-cell lymphomas. Am J Pathol 2002;160:1371-80.

24. Fang JM, Finn WG, Hussong JW, Goolsby CL, Cubbon AR, Variankojis D. CD 10 antigen expression correlates with the $\mathrm{t}(14 ; 18)(\mathrm{q} 32 ; \mathrm{q} 21)$ major breakpoint region in diffuse large B-cell lymphoma. Mod Pathol 1999;12:295-300.

25. Larocca LM, Capello D, Rinelli A, Nori S, Antinori A, Gloghini A, et al. The molecular and phenotypic profile of primary central nervous system lymphoma identifies distinct categories of the disease and is consistent with histogenetic derivation from germinal center-related B-cells. Blood 1998;92: 1011-9.

26. Skinnider FB, Horsman ED, Dupuis B, Gascoyne DR. Bcl-6 and Bcl-2 protein expression in Diffuse Large B-Cell Lymphoma and Follicular Lymphoma: Correlation With 3q27 and 18q21 chromosomal abnormalities. Hum Pathol 1999; 30:803-8.

27. Dogan A, Bagdi E, Munson P, Isaacson PG. CD 10 and BCL-6 expression in paraffin sections of normal lymphoid tissue and B-cell lymphomas. Am J Surg Pathol 2000;26:846-52.

28. King BE, Chen C, Locker J, Kant J, Okuyama K, Falini B, et al. Immunophenotypic and genotypic markers of follicular center cell neoplasia in diffuse large B-cell lymphomas. Mod Pathol 2000;13:1219-31.

29. Dunphy CH, Polski JM, Lance Evans H, Gardner LJ. Paraffin immunoreactivity of CD10, CDw75 and bcl6 in follicle center cell lymphoma. Leuk Lymphoma 2001;41:585-92.

30. Ree HJ, Yang WI, Kim CW, Huh J, Lee SS, Cho EY, et al. Coexpression of Bcl-6 and CD 10 in diffuse large B-cell lymphomas: significance of Bcl-6 expression patterns in identifying germinal center B-cell lymphoma. Hum Pathol 2001;32:954-62.

31. Barrans LS, Carter I, Owen GR, Davies EF, Patmore DR, Haynes PA, et al. Germinal center phenotype and bcl-2 expression combined with the International Prognostic Index improves patient risk stratification in diffuse large B-cell lymphoma. Blood 2002;99:1136-43.

32. Huang JZ, Sanger WG, Greiner TC, Staudt LM, Weisenburger DD, Pickering DL, et al. The $\mathrm{t}(14 ; 18)$ defines a unique subset of diffuse large B-cell lymphoma with a germinal center B-cell gene expression profile. Blood 2002;99:2285-90.

33. Arber DA, Weiss LM. CD10: a review. Appl Immunohistochemisrty 1997;5:125-40.

34. Ohshima K, Kawasaki C, Muta H, Deyev V, Haraoka S, Suzumiya $\mathrm{J}$, et al. $\mathrm{CD} 10$ and Bcl10 expression in diffuse large B-cell lymphoma: CD10 is a marker of improved prognosis. Histopathology 2002;39:156-62.

35. Xu Y, McKenna RW, Kroft SH. Comparison of multiparameter flow cytometry with cluster analysis and immunohistochemistry for the detection of CD 10 in diffuse large B-cell lymphomas. Mod Pathol 2002;15:413-9.

36. Allman D, Jain A, Dent A, Maile RR, Selvaggi T, Kehry MR, et al. Bcl-6 expression during B-cell activation. Blood 1996;87: 5257-68.

37. Albagli O, Lantoine D, Quief S, Quignon F, Englert C, Kerckaert JP, et al. Overexpressed BCL6 (LAZ3) oncoprotein triggers apoptosis, delays $\mathrm{S}$ phase progression and associates with replication foci. Oncogene 1999;18:5063-75.
38. Shaffer AL, Yu X, Boldrick J, Chan EP, Staudt LM. BCL-6 represses genes that function in lymphocyte differentiation, inflammation and cell cycle control. Immunity 2000;13:199212.

39. Hosokawa Y, Maeda Y, Seto M. Target genes downregulated by the BCL-6/LAZ3 oncoprotein in mouse Ba/F3 cells. Biochem Biophys Res Commun 2001;283:563-8.

40. Shvarts A, Brummelkamp RT, Scheeren F, Koh E, Daley QG, Spits $\mathrm{H}$, et al. A senescence rescue screen identifies BCL6 as an inhibitor of anti-proliferative p19ARF-p53 signaling. Genes Dev 2002;16:681-6.

41. Kumagai T, Miki T, Kikuchi M, Fukuda T, Miyasaka N, Kamiyama R, et al. The proto-oncogene bcl6 inhibits apoptotic cell death in differentiation-induced mouse myogenic cells. Oncogene 1999;18:467-75.

42. Yamochi T, Kaneita Y, Akiyama T, Mori S, Moriyama M. Adenovirus-mediated high expression of BCL-6 in CV-1 cells induces apoptotic cell death accompanied by downregulation of BCL-2 and BCL-X (L). Oncogene 1999;18: 487-94.

43. Kojima S, Hatano M, Okada S, Fukuda T, Toyama Y, Yuasa S, et al. Testicular germ cell apoptosis in bcl6-deficient mice. Development 2001;128:57-65.

44. Zhang H, Okada S, Hatano M, Okabe S, Tokuhisa T. A new functional domain of Bcl6 family that recruits histone deacetylases. Biochim Biophys Acta 2001;1540:188-200.

45. Baron BW, Anastasi J, Thirman JM, Furukawa Y, Fears S, Kim $\mathrm{CD}$, et al. The human programmed cell death-2 (PDCD2) gene is a target of BCL6 repression: implication for a role of BCL6 in the down-regulation of apoptosis. Proc Natl Acad Sci U S A 2002;99:2860-5.

46. Tang TTL, Dowbenko D, Jackson A, Toney L, Lewin DA, Dent $\mathrm{AL}$, et al. The forkhead transcription factor AFX activates apoptosis by induction of the bcl6 transcriptional repressor. J Biol Chem 2002;277:14255-65.

47. Martinez-Valdez H, Guret C, de Bouteiller O, Fugier I, Banchereau J, Liu YJ. Human germinal center B cells express the apoptosis-inducing genes Fas, c-myc, P53, and Bax but not the survival gene bcl-2. J Exp Med 1996;183:971-7.

48. Cutrona G, Dono M, Pastorino S, Ulivi M, Burgio VL, Zupo S, et al. The propensity to apoptosis of centrocytes and centroblasts correlates with elevated levels of intracellular myc protein. Eur J Immunol 1997;27:234-8.

49. Cutrona G, Leanza N, Ulivi M, Melioli G, Burgio VL, Mazzarello G, et al. Expression of CD10 by human T cells that undergo apoptosis both in vitro and in vivo. Blood 1999;94: 3067-76.

50. Cutrona G, Tasso P, Dono M, Roncella S, Ulivi M, Carpaneto $\mathrm{EM}$, et al. CD 10 is a marker for cycling cells with propensity to apoptosis in childhood ALL. Br J Cancer 2002;86:1776-85.

51. Dono M, Burgio VL, Tacchetti C, Favre A, Augliera A, Zupo S, et al. Subepithelial B cells in the human palatine tonsil. I. Morphologic, cytochemical and phenotypic characterization. Eur J Immunol 1996;26:2035-41.

52. Tzardi M, Kouvidou C, Panayiotides J, Stefanaki S, Koutsoubi $\mathrm{K}$, Zois E, et al. Expression of p53, mdm2 and p21/waf-1 proteins in non-Hodgkin's lymphomas. J Clin Pathol (Mol Pathol) 1996;49:M278-83.

53. Bai M, Vlachonikolis J, Agnantis NJ, Tsanou E, Dimou S, Nicolaides C, et al. Low expression of p27 protein combined with altered p53 and $\mathrm{Rb} / \mathrm{p} 16$ expression status is associated with increased expression of cyclin A and cyclin B1 in diffuse large B-cell lymphomas. Mod Pathol 2001;14:1105-13.

54. Bai M, Tsanou E, Agnantis NJ, Chaidos A, Dimou D, Skyrlas A, et al. Expression of cyclin D3 and cyclin E and identification of distinct clusters of proliferation and apoptosis in diffuse large B-cell lymphomas. Histol Histopathol (in press). 
55. Bai M, Agnantis NJ, Kamina SA, Demou A, Zagorianakou PS, Katsaraki A, et al. The in vivo cell kinetics in breast carcinogenesis. Breast Cancer Res 2001;3:276-83.

56. Moller MB, Kania PW, Ino Y, Gerdes AM, Nielsen O, Louis $\mathrm{DN}$, et al. Frequent disruption of the RB1 pathway in diffuse large B cell lymphoma: prognostic significance of E2F-1 and p161NK4A. Leukemia 2000;14:898-904.

57. Gronbaek K, de Nully Brown P, Moller MB, Nedergaard T, Ralfkiaer E, Moller P, et al. Concurrent disruption of p16INK4a and the ARF-p53 pathway predicts poor prognosis in aggressive non-Hodgkin's lymphoma. Leukemia 2001;14: 1727-35.

58. Sanchez-Beato M, Saez AI, Navas IC, Algara P, Sol Mateo M, Villuendas R, et al. Overall survival in aggressive B-cell lymphomas is dependent on the accumulation of alterations in p53, p16 and p27. Am J Pathol 2001;159:205-13.

59. Lossos IS, Jones CD, Warnke R, Natkunam Y, Kaizer H, Zehnder JL, et al. Expression of a single gene BCL-6, strongly predicts survival in patients with diffuse large B-cell lymphoma. Blood 2001;98:945-51. 